\title{
Análise do crédito do PRONAF no estado de Goiás no período de $2000-2011^{1}$
}

\author{
Gilberto José de Faria Queiroz ${ }^{2}$ \\ Divina Aparecida Leonel Lunas 3 \\ Ozamir Alves Frias ${ }^{4}$
}

\begin{abstract}
RESUMO
O artigo aborda a questão da criação do Programa de Fortalecimento da Agricultura Familiar (Pronaf), considerado o principal instrumento da política agrícola brasileira para profissionalização e a inserção do agricultor familiar no mercado. O texto trata do marco legal da constituição da legislação do Pronaf e sua evolução em termos de número de contratos e volume de recursos disponibilizados. Foca, ainda, na questão da distribuição dos recursos para o Estado de Goiás, analisando a sua evolução nas modalidades de custeio, financiamento e total para o segmento agrícola e pecuário. A análise da evolução é feita para o período de 2000 a 2011 através dos dados coletados no Banco Central do Brasil através do Anuário Estatístico do Crédito Rural. Os dados pesquisados indicam uma dinâmica firme e de consolidação do número de contratos e volume de operações do Pronaf em Goiás. A atividade da pecuária tem apresentado as maiores taxas de crescimento e participação no total dos recursos disponibilizados. $\mathrm{O}$ volume de recursos destinados aos investimentos da pecuária para os produtores do Pronaf em Goiás apresentou com crescimento mais significativo do período analisado. A modalidade de aquisição de animais apresenta a maior participação entre as opções de investimentos da pecuária indicando uma estratégia de melhoria dos rebanhos dos produtores rurais familiares. Conclui-se que esta opção tem como meta a consolidação desta atividade para a geração e inserção do produtor familiar no mercado goiano.
\end{abstract}

Palavras-chave: legislação, inserção, consolidação, fortalecimento, agricultura familiar.

\section{INTRODUÇÃO}

Com a publicação do Anuário Estatístico do Crédito Rural o Banco Central do Brasil divulga e analisa os dados e informações dos impactos do financiamento da atividade

\footnotetext{
${ }^{1}$ Pesquisa financiada com apoio da FAPEG - Fundação de Amparo à Pesquisa do Estado de Goiás através da bolsa de DCR para o primeiro autor da pesquisa - Projeto com o Título "Dinâmica e análise do acesso ao crédito rural da agricultura familiar no Sudoeste Goiano, 2000 a 2012".

${ }^{2}$ Doutor em Geografia pelo Instituto de Economia pela Universidade Federal de Uberlândia. Bolsista DCRFAPEG/CNPQ. UEG, Campus Santa Helena de Goiás. E-mail: gjfqueiroz@ gmail.com

${ }^{3}$ Doutora em Desenvolvimento Econômico pela Universidade Estadual de Campinas (Unicamp). Professora do Mestrado Interdisciplinar Territórios e Expressões Culturais no Cerrado, Campus Anápolis de Ciências Socioeconômicas e Humanas - Universidade Estadual de Goiás. Bolsista do PROPIB (Programa de Incentivo à Pesquisa e Produção Científica). E-mail: divina.lunas@ueg.br

${ }^{4}$ Graduando em Sistema de Informações. UEG, Campus Anápolis de Ciências Exatas e Tecnológicas Henrique Santillo. E-mail: ozamir.frias@gmail.com
} 
agropecuária nacional de cada ano. A base da abordagem é do Crédito Rural Institucionalizado pela Lei n. 4,829, de 5 de novembro de 1965, e regulamentado pelo Manual de Crédito Rural (MCR) anexo à Resolução CMN n. 580, de 29 de novembro de 1979, e atualizações posteriores (BANCO CENTRAL DO BRASIL, 2010).

De acordo com o marco legal o crédito rural tem como objetivos principais: i) estimular os investimentos rurais na produção, armazenamento, beneficiamento e industrialização de produtos agropecuários; ii) favorecer o oportuno e adequado custeio da produção e da comercialização de produtos agropecuários; iii) incentivar a introdução de métodos racionais no sistema de produção visando ao aumento da produtividade, à adequada preservação do meio ambiente, e, especialmente, à melhoria da qualidade de vida dos produtores, comumente medida pelo Índice de Desenvolvimento Humano (IDH) da população rural.

Segundo o Banco Central, o forte crescimento do setor primário da economia nas últimas décadas, além de decorrer dos investimentos aplicados na pesquisa agropecuária e na dinamização dos processos produtivos, se deve ao aumento significativo e continuado da oferta de Crédito Rural, inclusive através do Pronaf para a agricultura familiar. A criação do Pronaf é a principal mudança no direcionamento dos recursos com foco para o produtor familiar brasileiro.

Com essas considerações, esse trabalho visa analisar quantitativamente a evolução do crédito rural do PRONAF no Estado de Goiás no período de 2000 a 2011. É necessário abordar o financiamento para custeio e investimento, tanto para a atividade agrícola quanto para a pecuária.

Assim como viabiliza uma melhor compreensão da dinâmica do financiamento, as análises das diversas relações, como: I) custeio/investimento para a atividade agrícola e pecuária; II) custeio agrícola/custeio pecuário; III) investimento agrícola/investimento pecuário; IV) financiamento total agrícola/pecuária. Os dados foram coletados no através do Banco Central do Brasil e a publicação anual dos relatórios do crédito rural.

$\mathrm{O}$ artigo está dividido em quatro principais seções. Esta primeira que aborda de forma geral o foco do estudo. A segunda seção que trata dos aspectos legais da criação do Pronaf, a terceira seção com a análise dos dados para o Estado de Goiás e última seção que apresenta as principais conclusões deste estudo 


\section{REFERENCIAL E ASPECTOS LEGAIS}

\subsection{CONSIDERAÇÕES INICIAIS DA LEI 11.326}

Vale ressaltar os principais aspectos conceituais e legais da Lei 11.326. De início, os Artigos Primeiro e Segundo indicam ações de políticas públicas direcionadas tanto à Agricultura Familiar quanto aos Empreendimentos Familiares Rurais, articuladas, em todas as fases de sua formulação e implantação, com a política agrícola, na forma da lei, e com as políticas voltadas para a reforma agrária. Então, ao analisar essa política e seus resultados operacionais torna-se necessário levar em conta os impactos e a evolução concomitante da política agrícola para o país.

No Artigo Terceiro, considera agricultor familiar e empreendedor familiar rural aquele que pratica atividades no meio rural, atendendo, simultaneamente, aos seguintes requisitos: I - não detenha, a qualquer título, área maior do que 4 (quatro) módulos fiscais; II utilize predominantemente mão-de-obra da própria família nas atividades econômicas do seu estabelecimento ou empreendimento; III - tenha percentual mínimo da renda familiar originada de atividades econômicas do seu estabelecimento ou empreendimento, na forma definida pelo Poder Executivo; IV - dirija seu estabelecimento ou empreendimento com sua família (BRASIL, 2006). Como fica estabelecido no Parágrafo Primeiro, o disposto no inciso I do caput deste artigo não se aplica quando se tratar de condomínio rural ou outras formas coletivas de propriedade, desde que a fração ideal por proprietário não ultrapasse 4 (quatro) módulos fiscais.

A condição delimitada quanto à área da propriedade, de até 4 (quatro) módulos fiscais, passa a ser outro parâmetro de análise operacional dos resultados do PRONAF.

São também beneficiários desta Lei: silvicultores, aquicultures, extrativistas, pescadores, povos indígenas, integrantes de comunidades remanescentes de quilombos rurais e demais povos e comunidades tradicionais que atendam simultaneamente aos incisos II, III e IV do caput do Artigo Terceiro e que promovam o manejo sustentável dos ambientes dos seus empreendimentos familiares.

Posteriormente, com o advento da Lei 12.058, de 13 de outubro de 2009, no seu Artigo 23, promove substancial abertura e aprimoramento no Artigo Terceiro da Lei 11.326, visando adequar a operacionalização da lei para atender e incluir os diferentes segmentos desse heterogêneo grupo social da agricultura familiar, que passa a vigorar acrescido dos Parágrafos Terceiro e Quarto. 
O Parágrafo Terceiro determina que o Conselho Monetário Nacional - CMN pode estabelecer critérios e condições adicionais de enquadramento para fins de acesso às linhas de crédito destinadas aos agricultores familiares, de forma a contemplar as especificidades dos seus diferentes segmentos.

E, o Quarto estabelece que podem ser criadas linhas de crédito destinadas às cooperativas e associações que atendam a percentuais mínimos de agricultores familiares em seu quadro de cooperados ou associados e de matéria-prima beneficiada, processada ou comercializada oriunda desses agricultores, conforme disposto pelo CMN.

Esses aprimoramentos na legislação foram decisivos para a ampliação crescente, nos anos vindouros, da operacionalização do PRONAF quanto à viabilização do acesso ao crédito para os grupos mais fragilizados, de muito baixa renda, da agricultura familiar. Por outro lado, cria condições administrativas e operacionais de inclusão aos financiamentos especiais para grupos de agricultores familiares de cooperativas e associações, tanto para projetos de produção quanto de processamento dos seus produtos.

\subsection{O financiamento da agricultura familiar}

Para Souza e Caume (2008) o PRONAF passou a ser a principal política pública do governo federal de apoio ao desenvolvimento rural, por meio do fortalecimento da agricultura familiar, em função de sua importância para a produção de alimentos para o mercado interno, para as agroindústrias e para as exportações brasileiras e, principalmente como geradora de postos de trabalho e renda. Segundo orientações institucionais, o PRONAF busca construir um padrão de desenvolvimento sustentável para os agricultores familiares e suas famílias, através do incremento e da diversificação da capacidade produtiva, com o consequente crescimento dos níveis de emprego e renda, proporcionando bem-estar social e qualidade de vida. Além do que, tem como ponto forte o gerenciamento das ações através da gestão social, cujo objetivo é a promoção de uma melhor gestão do orçamento público, da democratização do crédito, dos serviços de apoio e da infraestrutura necessária à consolidação e à estabilização socioeconômica dos agricultores familiares.

Fazendo uma análise das diferenças nos financiamentos concedidos para a agricultura familiar e não-familiar, no período de 1999 a 2009, SOUZA (2011) constatou que cerca de $80 \%$ dos agricultores, familiares ou não, não obtiveram crédito no ano de 2006. Somente na região Sul esse índice é mais baixo, situando-se na faixa de 60 a $70 \%$ dos agricultores. Entretanto, há diferenças entre os dois segmentos, pois, no segmento não- 
familiar, é menor o percentual de estabelecimentos que não precisaram de crédito, e mais expressiva a parcela dos que, por receio de dívida, pelas barreiras impostas pela burocracia ou por outro motivo, não tiveram acesso aos financiamentos.

No período, o valor dos recursos concedidos para o financiamento da agricultura familiar não chegou a representar mais do que $15 \%$ dos recursos de crédito. Constatou-se que o volume de crédito por estabelecimento e por unidade de mão-de-obra empregada é muito maior no segmento não-familiar do que no familiar. Por outro lado, ainda que o segmento não-familiar ocupe a maior parte da área total de estabelecimentos agropecuários no país, o crédito recebido por unidade de área, nesse segmento, é proporcionalmente mais elevado do que o que se observa no segmento familiar.

O volume de crédito do Pronaf, por unidade de área do segmento familiar, equivale a menos da metade do crédito concedido a cada unidade de área da agricultura não-familiar. Constatou-se que o crédito concedido por equivalente-homem da agricultura não-familiar é quatorze vezes e meia o valor concedido por pessoa ocupada na agricultura familiar, mediante o Pronaf. Tal constatação reflete, de um lado, a grande preponderância do segmento familiar no que concerne à ocupação de mão-de- obra; de outro, é um indício de que este segmento tem permitido ocupar mão-de-obra a um custo muito inferior ao do segmento não-familiar, sabidamente utilizador de tecnologias menos intensivas em trabalho.

Fato semelhante ocorre quando se compara o valor dos recursos concedidos a ambos os segmentos com a participação deles no valor da produção agropecuária, que, como se sabe, é proporcionalmente maior no segmento não-familiar. Estimou-se que, para cada $\mathrm{R} \$ 1.000,00$ gerados no segmento familiar, foram utilizados cerca de $\mathrm{R} \$ 132,00$ de crédito, ao passo que o segmento não-familiar financiou cerca de $\mathrm{R} \$ 490,00$, quase a metade do valor produzido, o equivalente a 3,71 vezes o volume de crédito por valor produzido na agricultura familiar.

Portanto, todas as estimativas indicam que, apesar de sua importância, a agricultura familiar tem empregado, e também recebido, em termos proporcionais, um volume de recursos nitidamente inferior ao concedido ao segmento não-familiar. Ainda que a concessão de recursos para financiamento dos agricultores familiares implique maiores custos para arcar com a redução das taxas de juros, os indicadores aqui estimados mostram que o volume de financiamento obtido por esse segmento não condiz com sua real importância. Elevar o montante de recursos e reduzir as limitações para sua efetiva utilização são sugestões que, em princípio, podem ser inferidas a partir do estudo. 
Tomando um exemplo regional, através de pesquisa sobre o perfil da agricultura familiar no Sudoeste de Goiás, (MORAES; LIMA, 2005) constataram que a agricultura familiar nos municípios estudados (Rio Verde, Santa Helena de Goiás, Jataí e Chapadão do Céu) apresenta um baixo padrão tecnológico, principalmente quanto ao maquinário e aos insumos agrícolas, sendo necessária uma revisão nos valores liberados para o custeio e investimentos neste segmento. Percebe-se na agricultura familiar da região uma reprodução do quadro nacional, ou seja, a falta de capital e estrutura tornou este segmento altamente dependente de políticas públicas. Sem uma organização de alternativas produtivas pelos poderes públicos da região comprometidos no fornecimento de recursos com fiscalização e conscientização, provavelmente as propriedades familiares serão abandonadas na busca de outras alternativas no setor urbano.

Esse é o interesse maior do caso do Pronaf. Ele mostra que políticas voltadas a promover o crescimento econômico com base na distribuição de ativos estão permanentemente ameaçadas pela distância potencial entre racionalidade econômica e necessidades sociais. Isso é verdade para o Pronaf, para a reforma agrária, para o microcrédito urbano, em suma, para qualquer política que procure estimular as capacidades produtivas das populações que hoje vivem em situação de pobreza. É no enfrentamento desse conflito potencial que se formam as instituições com base nas quais esses programas são levados à prática. Os resultados desse conflito são, evidentemente, os mais variados, mas o sucesso do esforço em promover o uso eficiente dos recursos que chegam a populações que vivem em situação de pobreza depende, evidentemente, do formato das instituições que vão sendo construídas ao longo dos próprios programas com tais objetivos (ABRAMOVAY; PIKETTY, 2005).

De acordo com o Ministério do Desenvolvimento Agrário (2011) o PRONAF, é uma das políticas públicas do Governo Federal para apoiar os agricultores familiares. Outros públicos atendidos são: pescadores artesanais, extrativistas, silvicultores, aquicultores, maricultores, piscicultores, comunidades quilombolas, povos indígenas, criadores de animais silvestres. A coordenação do Programa é do Ministério do Desenvolvimento Agrário (MDA). A execução é feita de forma descentralizada e conta com a parceria das organizações dos agricultores familiares, dos governos estaduais e municipais, das organizações governamentais e não governamentais de assistência técnica e extensão rural, das cooperativas de crédito e de produção, dos agentes financeiros, do Serviço Brasileiro de Apoio às Micro e Pequenas Empresas (SEBRAE) e outros. 


\subsection{Evolução do Pronaf}

O Ministério do Desenvolvimento Agrário traça um resumo de diagnótico da evolução do Pronaf do período compreendido das safras dos anos 1999/2000 a 2008/2009. Demonstra que as contratações do Crédito - Pronaf apresentam crescimento sustentado ao longo dos anos. Em 1999/2000, o Pronaf abrangia 3.403 municípios, passando para 4.539 municípios no ano seguinte, o que representou um aumento de $33 \%$ na cobertura de municípios, ou seja, a ampliação de mais de 1.100 municípios em apenas um ano. A ampliação de municípios atendidos continuou em cada ano agrícola, sendo que em 2005/2006houve a inserção de quase 1.960 municípios em relação à 1999/2000. Em 2007/2008, foram atendidos 5.379 municípios, o que representou um crescimento de $58 \%$ em relação à 1999/2000, com a inserção de 1.976 municípios. (BRASIL, 2011).

Quanto ao montante disponibilizado aos agricultores também cresceu. Em 1999/2000, foram disponibilizados pouco menos de $\mathrm{R}$ \$ 3,3 bilhões com uma execução de 66\%. No ano agrícola de 2003/2004, houve o primeiro grande incremento no montante, com um crescimento de 65\% em relação à 1999/2000, sendo ofertados R \$ 5,4 bilhões aos agricultores e com uma execução de 83\% do valor disponibilizado. Em 2006/2007, o montante disponibilizado para financiamento do Pronaf chegou a R\$ 10 bilhões, representando um crescimento em relação à 1999/2000 de 205\% e com uma taxa de execução de $84 \%$ (Figura 1).

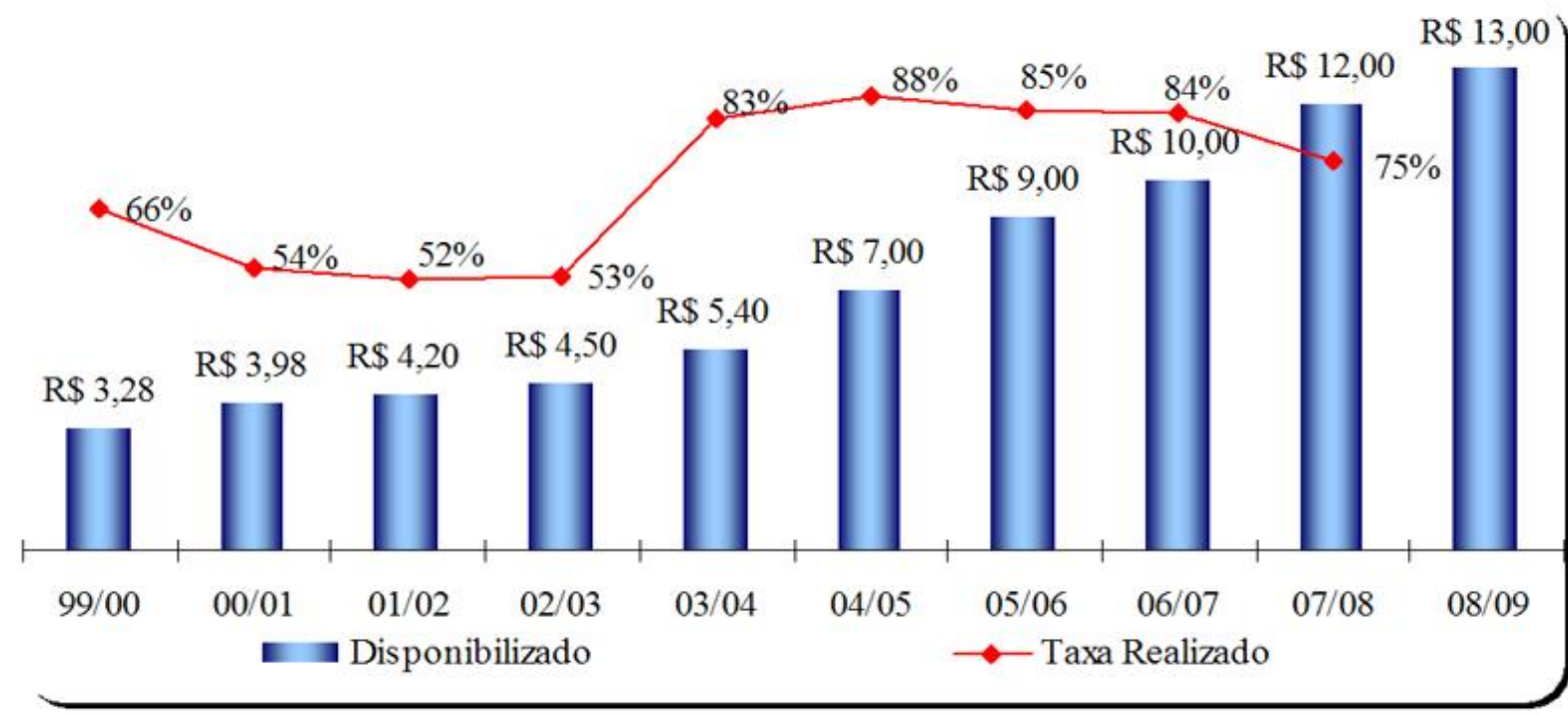

Fonte: BACEN (2013).

FIGURA 1 - Evolução dos Recuros disponibilizados pelo Pronaf ,safras 1999/2000 a 2008/2009, em bilhões de reais. 
A primeira grande evolução no montante financiado pelos agricultores familiares foi em 2003/2004, fechando uma contratação de R \$ 4,49 bilhões, representando uma evolução de 109\% em relação a 1999/2000. Nos anos seguintes, o crescimento manteve-se sustentado. Em 2004/2005 foi de 185\%, representando um financiamento de R \$ 6,13 bilhões. Em 2005/2006, foram financiados R \$ 7,61 bilhões com uma evolução de 254\%, sendo que em 2007/2008 rompeu-se a casa dos 300\%, perfazendo um financiamento de R 9 bilhões. (Figura 2).

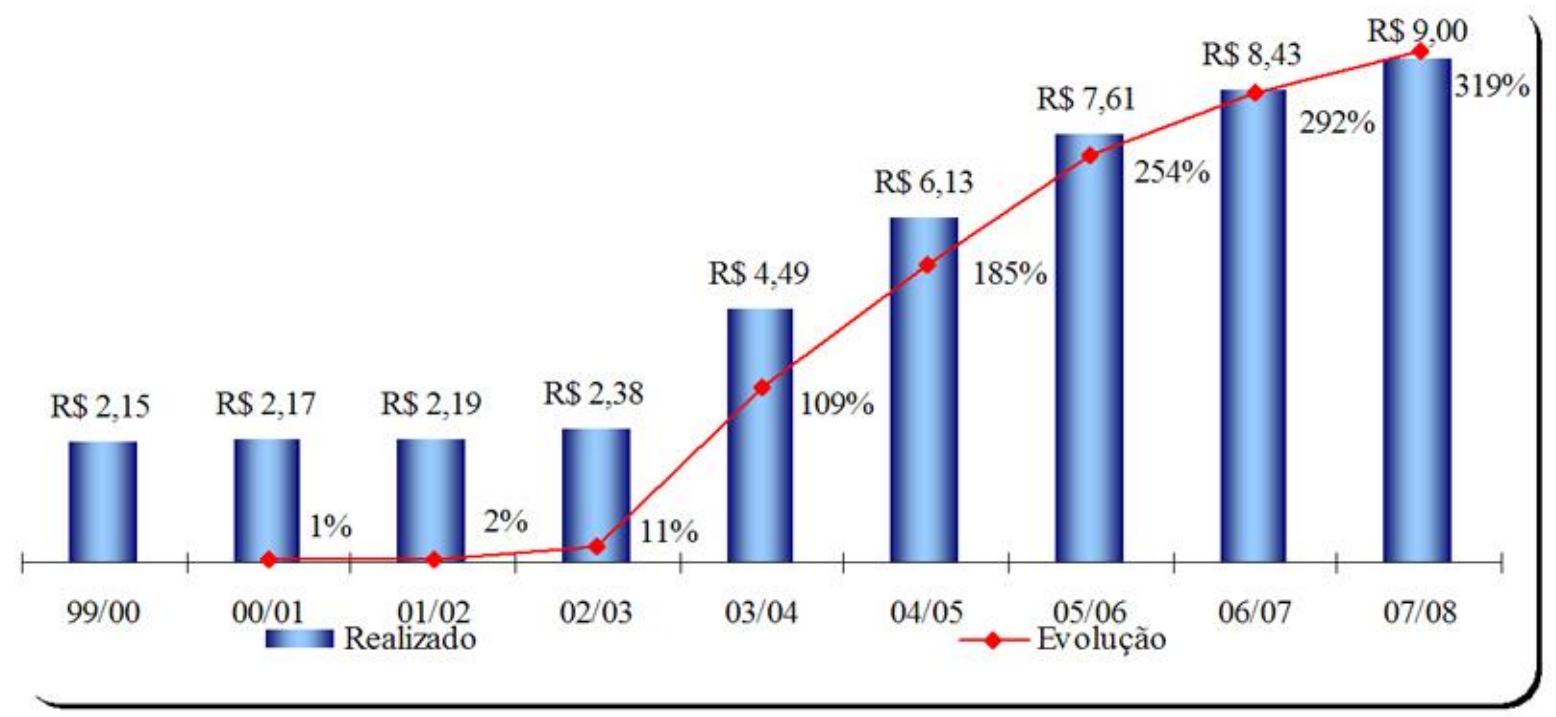

Fonte: BACEN (2013).

FIGURA 2 - Evolução dos recursos utilizados do Pronaf, safras 1999/2000 a 2008/2009, em bilhões de reais.

Vale ressalvar que esse diagnóstico evolutivo e quantitativo do Ministério do Desenvolvimento Agrário do Pronaf, do período compreendido das safras dos anos 1999/2000 a 2008/2009, não contribui significativamente para esclarecer as contradições das condições de acesso ao crédito visando distribuição ou produção de renda para o segmento familiar. (BRASIL, 2011). O Pronaf é um imenso esforço para reduzir essa distância e é exatamente aí que, desde seu início, concentram-se seus maiores problemas e tensões.

Ressalta-se que o agricultor familiar foi então definido como aquele que conta fundamentalmente com a mão-de-obra da família para levar adiante seu negócio (permitindo empregar no máximo dois assalariados permanentes), em que $80 \%$ do faturamento tivesse origem nas atividades do estabelecimento agropecuário e cuja renda anual não ultrapassasse R\$ 27,5 mil. Para beneficiar-se do Pronaf, o agricultor deveria encaminhar ao banco um “certificado de aptidão", produzido seja pelo sindicato local, seja pela agência de extensão rural, que atestava sua condição de agricultor familiar. Esse procedimento, aparentemente burocrático, foi conduzido com relativa facilidade graças à capilaridade, pelo interior do País, 
tanto do sindicalismo como da extensão rural. Todas as avaliações sobre os dois primeiros anos de execução do Pronaf mostram que o Programa atingiu, de fato, agricultores familiares e que seus desvios em direção a um público que não fizesse parte desse universo foram inexpressivos (ABRAMOVAY, 1999; BELIK, 1999; SILVA, 1999).

Nem todos os agricultores familiares, porém, beneficiaram-se do Programa. Em 1996, os contratos de custeio do Pronaf não atingiram sequer $10 \%$ do universo total de agricultores familiares do País. No ano seguinte, o Programa reforçou-se e o crescimento, desde então, foi contínuo.

Além disso, a distribuição dos créditos do Pronaf estava intensamente marcada por uma tríplice concentração. Em primeiro lugar, eram beneficiados sobretudo os mais prósperos agricultores familiares, aqueles de maior renda e, provavelmente, os que já mantinham relações comerciais com o setor bancário. Em segundo, os bancos tendiam a privilegiar agricultores familiares que trabalhavam com mercados mais dinâmicos, mais estáveis, e beneficiavam, então, preferencialmente, os agricultores integrados à agroindústria.

No Estado de Santa Catarina, por exemplo, nada menos que 55\% dos recursos do Pronaf voltaram-se ao cultivo de fumo em 1997. Enfim, exprimindo a concentração regional, em 1997, a maior parte dos créditos foram distribuídos aos três Estados do Sul (Santa Catarina, Rio Grande do Sul e Paraná), onde a agricultura familiar é mais organizada e tem melhor integração aos mercados (ABRAMOVAY, 1999).

De acordo com Abramovay; Piketty (2005) não há dúvida de que os subsídios do Pronaf permitiram ampliar as capacidades de geração de renda das populações pobres do Brasil. Pesquisa realizada em 1999 mostra que, até aquele ano, 56\% dos tomadores de recursos do Pronaf nunca tinham recebido financiamento bancário (BRASIL, 1999). Apesar disso, a atual forma de apoio à agricultura familiar por meio do crédito sofre restrições.

Seria impossível financiar as atividades agropecuárias sem algum tipo de subsídio às taxas de juros, cujo nível de mercado é impraticável para essa atividade, mesmo no segmento patronal. Oferecer subsídios diferenciados aos agricultores de acordo com seu nível de renda talvez não seja, porém, a melhor forma de lhes transferir renda. Nos casos extremos em que se devolve um valor inferior ao montante emprestado, é impossível saber se o dinheiro foi utilizado para uso produtivo ou pelo interesse geral de se tomar um empréstimo nessas condições.

Os custos da intermediação, ali onde o risco bancário existe, é a expressão monetária da distância social entre agricultores e sistema financeiro. Na verdade, os grandes 
beneficiários com o pagamento desses custos são os bancos comerciais pertencentes ao Estado. As cooperativas de créditos vinculadas às associações de agricultores familiares (como o sistema Cresol de crédito solidário), que fazem empréstimos, mas recebem só uma pequena parte da remuneração recebida pelos Bancos (JUNQUEIRA; ABRAMOVAY, 2005), provam que a intermediação bancária é excessiva e que existem alternativas a ela.

As cooperativas operam com custos menores, por serem mais próximas dos agricultores, o que reduz a assimetria de informação. Remover os obstáculos legais que até hoje os impedem de receber recursos para o Pronaf é uma das possibilidades para que o acesso aos recursos do Programa seja um caminho para a autonomia e a independência de seus beneficiários.

\section{RESULTADOS, DISCUSSÃO E ANÁLISE DOS DADOS}

\subsection{Pronaf Agrícola - o financiamento de custeio e investimento em Goiás}

Tomando o período de 2000 a 2011, os dados da Tabela 1 indicam uma dinâmica firme e de consolidação da gestão e da operacionalização do programa nacional de fortalecimento da agricultura familiar no Estado de Goiás. Apesar de uma irregularidade do número de contratos contemplados para o custeio agrícola, como de 3.250 no ano 2000 para 12.290 em 2004 e de 2.883 contratos no final da década, pode indicar uma afirmação econômica positiva dos usuários e produtores rurais remanescentes financiados nas atividades agrícolas. Dois outros fatores ajudam a corroborarem com essa assertiva.

Primeiro, o montante dos recursos alocados para o custeio agrícola de em torno de onze milhões de reais em 2000 cresceu, nominalmente, para mais de quarenta em 2011. A oferta do crédito foi maior em 2004 atingindo o valor de $\mathrm{R} \$ 61.663 .558,80$, financiando o maior número de contratos do período em estudo. Pode-se concluir que, anualmente, os montantes disponibilizados para o financiamento conseguem atender a demanda dos contratos, mesmo que não fossem os ideais. Os dados também indicam certa acomodação da oferta de crédito a partir de 2004, com decréscimos anuais até 2011, possivelmente causados pela inflação anual e o aumento dos custos da produção agrícola. Portanto, é pertinente a sugestão de revisão dessa política e a rápida atualização dos montantes para o financiamento do custeio agrícola. 
TABELA 1 - Pronaf agrícola - Custeio e Investimento - Estado de Goiás: 2000 -2011.

\begin{tabular}{rrrrrrr}
\hline Ano & \multicolumn{3}{c}{ Custeio } & \multicolumn{3}{c}{ Investimento } \\
\hline & $\begin{array}{c}\text { Contratos } \\
\left(\mathrm{N}^{\circ}\right)\end{array}$ & \multicolumn{1}{c}{$\begin{array}{c}\text { Valor } \\
(\mathrm{R} \$)\end{array}$} & $\begin{array}{c}\text { Média dos } \\
\text { Contratos }(\mathrm{R} \$)\end{array}$ & $\begin{array}{c}\text { Contratos } \\
\left(\mathrm{N}^{\circ}\right)\end{array}$ & \multicolumn{1}{c}{$\begin{array}{c}\text { Valor } \\
(\mathrm{R} \$)\end{array}$} & $\begin{array}{c}\text { Média dos } \\
\text { Contratos }(\mathrm{R} \$)\end{array}$ \\
\hline 2000 & 3.250 & $10.836 .813,16$ & $3.334,40$ & 186 & $873.323,32$ & $4.695,29$ \\
2001 & 3.414 & $12.668 .566,06$ & $3.710,77$ & 96 & $1.080 .821,25$ & $11.258,55$ \\
2002 & 4.105 & $12.003 .575,36$ & $2.924,14$ & 63 & $704.885,84$ & $11.188,66$ \\
2003 & 10.022 & $33.627 .016,90$ & $3.355,32$ & 140 & $1.686 .076,49$ & $12.043,40$ \\
2004 & 12.290 & $61.663 .558,80$ & $5.017,38$ & 121 & $1.924 .647,90$ & $15.906,16$ \\
2005 & 9.655 & $59.014 .894,42$ & $6.112,37$ & 219 & $2.159 .532,71$ & $9.860,88$ \\
2006 & 8.528 & $57.629 .029,03$ & $6.757,63$ & 227 & $2.473 .735,02$ & $10.897,51$ \\
2007 & 8.070 & $57.789 .707,98$ & $7.161,05$ & 184 & $1.678 .152,21$ & $9.120,39$ \\
2008 & 6.349 & $53.367 .991,47$ & $8.405,73$ & 249 & $4.754 .438,62$ & $19.094,13$ \\
2009 & 5.138 & $50.955 .664,41$ & $9.917,41$ & 629 & $16.453 .164,88$ & $26.157,65$ \\
2010 & 3.990 & $46.618 .403,04$ & $11.683,81$ & 836 & $12.086 .653,83$ & $14.457,72$ \\
2011 & 2.833 & $42.409 .876,73$ & $14.969,95$ & 550 & $14.261 .568,66$ & $25.930,12$ \\
\hline
\end{tabular}

Fonte: BACEN (2014).

Em segundo lugar, é bastante positivo, do ponto de vista econômico, o crescente aumento anual do valor médio dos contratos financiados verificados nessa série. Valores da média dos contratos, em torno de três mil reais em 2000 para seis mil em 2005 e chegando a quinze mil em 2011, podem indicar que certa parcela dos usuários está suportando o endividamento (usando bem o financiamento) e se afirmando nas atividades produtivas. Essa evolução pode ainda estar associada aos aumentos da produtividade agrícola e melhorias de inserção desses produtores nos mercados para comercialização dos seus produtos. Esses aspectos precisam ser pesquisados visando aperfeiçoamentos da política de crédito do Pronaf em Goiás.

Na Figura 3 apresenta-se a expansão do volume de recursos disponibilizados no custeio agrícola no período analisado, caracterizando o forte crescimento destes recursos destinados ao Estado de Goiás. A taxa geométrica de crescimento calculado neste período foi de $11 \%$. Verifica-se que o período de maior expansão é entre os anos de 2002 a 2004, após este período existe uma tendência de redução do volume distribuído.

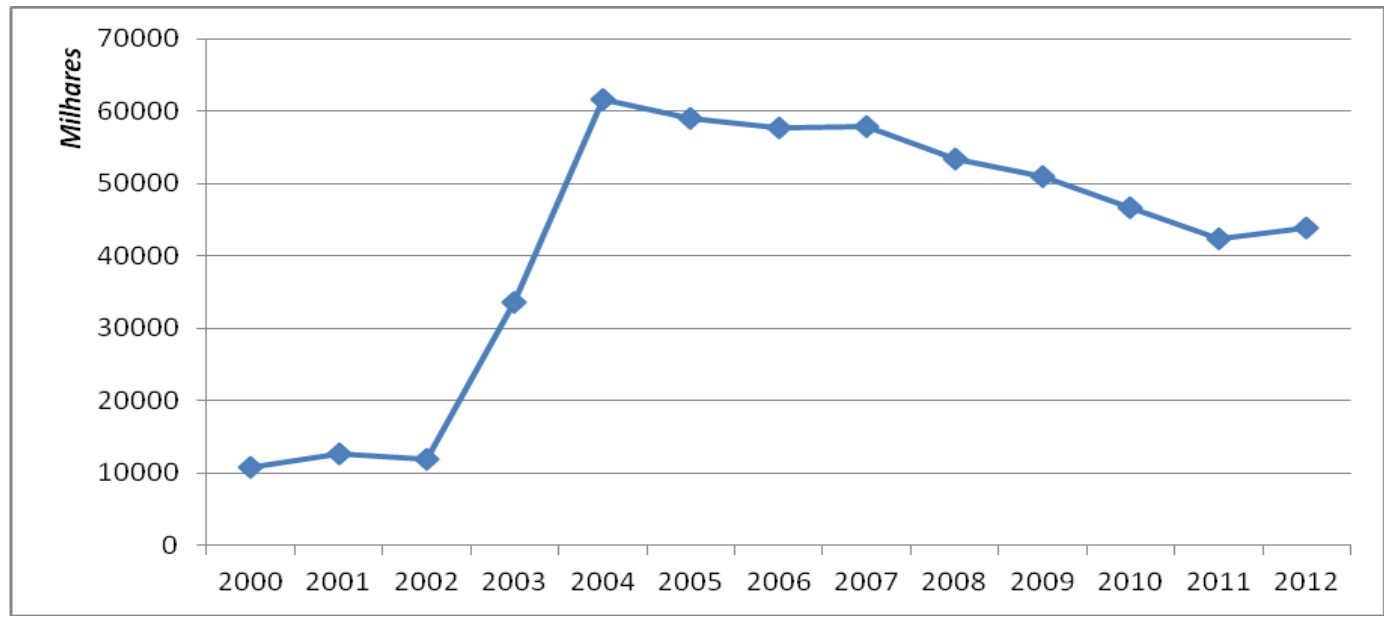

Fonte: BACEN (2014).

FIGURA 3 - Pronaf - Recursos para custeio agrícola no Estado de Goiás, 2000 a 2012. 
Para melhor compreensão do crédito agrícola da modalidade custeio, o destino e as aplicações dos recursos, a Tabela 2 apresenta as informações referentes aos anos de 2000, 2004, 2008 e 2011.

TABELA 2 - Principal atividade e principais produtos da modalidade de custeio agrícola financiados pelo Pronaf, no Estado de Goiás, nos anos 2000, 2004, 2008 e 2011.

\begin{tabular}{|c|c|c|c|c|c|c|c|c|}
\hline \multirow[t]{2}{*}{ Ano } & \multirow{2}{*}{$\begin{array}{l}\text { Contratos } \\
\left(\mathrm{N}^{0}\right)^{1}\end{array}$} & \multirow[t]{2}{*}{ Valor Total $(\mathrm{R} \$)^{2}$} & \multicolumn{2}{|c|}{ Modalidade $^{3}$} & \multicolumn{4}{|c|}{ Principais Produtos ${ }^{4}$} \\
\hline & & & Atividade & $\begin{array}{c}\text { Valor } \\
(\%)\end{array}$ & Nome & $\begin{array}{c}\text { Valor } \\
(\%)\end{array}$ & Nome & $\begin{array}{c}\text { Valor } \\
(\%)\end{array}$ \\
\hline 2000 & 3.250 & $10.836 .813,16$ & Lavoura & 22,33 & Milho & 40,64 & arroz & 10,54 \\
\hline 2004 & 12.290 & $61.663 .558,80$ & Lavoura & 99,97 & Milho & 56.33 & arroz & 13,69 \\
\hline 2008 & 6.349 & $53.367 .991,47$ & Lavoura & 100,00 & Milho & 53,15 & soja & 18,30 \\
\hline 2011 & 2.883 & $42.409 .876,73$ & Lavoura & 94,80 & Soja & 36,30 & milho & 34,77 \\
\hline
\end{tabular}

${ }^{1}$ Número total dos contratos de custeio agrícola. ${ }^{2}$ Valor total financiado. ${ }^{3}$ Em 2000, 2001, 2002, 2003 e 2004 existiam as modalidades de: Beneficiamento ou Industrialização, Crédito Rotativo e Lavoura. A partir de 2005 até 2011 o Crédito Rotativo foi eliminado e aparece a modalidade Extrativismo Espécies Nativas. Não existem registros de financiamento para Beneficiamento ou Industrialização e, apenas no ano de 2011 foi financiado um contrato de $\mathrm{R} \$ 50.000,00$ para Extrativismo Espécies Nativas. ${ }^{4}$ Os percentuais dos valores financiados dos principais são referentes aos valores financiados para lavoura. Fonte: BACEN (2014).

A Tabela 2 mostra a evolução do crédito de custeio agrícola assim como as principais finalidades, atividades e produtos financiados pelo Pronaf.

Pode-se constatar uma evidente irregularidade da evolução dos números de contratos contemplados no período de 2000 a 2011. A discrepância é evidente, como em 2004 foram 12.290 e em 2011 apenas 2.883 contratos. Foge ao objetivo desse trabalho abordar as causas dessa irregularidade, possivelmente advinda da gestão do programa, inadimplência ou outros problemas.

Os valores financiados, anualmente, no período, tiveram um crescente aporte a partir de 2000, com $\mathrm{R} \$ 10.836 .813,16$, atingindo o máximo valor em 2004, com $\mathrm{R} \$ 61.663 .558,80$. De 2005 foi decrescendo aos poucos até atingir o menor valor em 2011, com $\mathrm{R} \$ 42.409 .876,73$. Esse comportamento pode ser explicado pela elevada variação anual dos contratos financiados, mas, também pode estar associada a incapacidade da agricultura familiar se afirmar na produção de lavouras mais competitivas e de maior produtividade com inserção nos mercados.

Quanto à modalidade e atividade contemplada, de 2001 a 2002, os valores do Crédito Rotativo suplantaram os da Lavoura. Já em 2003, o Crédito Rotativo teve $\mathrm{R} \$ 4.378 .380,61$ e Lavoura com $\mathrm{R} \$ 29.248 .636,29$. A partir de 2004, todos os recursos do Custeio foram destinados para Lavoura.

Em relação aos principais produtos agrícolas custeados vale ressalvar alguns aspectos importantes. Até 2008, o milho foi o produto contemplado, anualmente, com em 
torno de 50\% dos recursos de Lavoura. A partir de 2009, a soja passa a receber, juntamente, com o milho, a maior parte dos recursos. O produto arroz tem certa importância de financiamento até 2004, depois é rápido o decréscimo do se aporte tendo, 2011, apenas o financiamento de $\mathrm{R} \$ 255.125,90$. Dados do produto mandioca não aparecem na tabela abaixo, mas é preciso uma explicação. Os dados da série indicam que o maior valor financiado para a mandioca foi em 2004, para 1.677 contratos, de $\mathrm{R} \$ 5.793 .800,04$, o equivalente à 9,40\% do montante da Lavoura no mesmo ano. Já, em 2011, esse percentual era de apenas 5,97.

Em síntese, considerando que o milho não pode mais ser considerado como um produto de base alimentar de sobrevivência, mas sim, junto com a soja, do complexo agroindustrial, pode-se concluir que o custeio agrícola do Pronaf prioriza esses dois produtos. Produtos alimentares típicos, como feijão, arroz e mandioca, são menos proporcionalmente menos financiados pelo Pronaf. Produtos como da fruticultura e hortaliças, que possuem mais valor em mercados locais, não são discriminados nos dados da série.

A finalidade de investimento agrícola do Pronaf, no período em estudo, contemplou as seguintes modalidades para financiamento: Animais de Serviço, Formação de Culturas Perenes, Máquinas e Equipamentos, Melhoramento de Explorações, Outras Aplicações e Veículos. Os dados analisados indicam uma evolução ainda mais significativa na modalidade de investimento agrícola com uma taxa geométrica de expansão de $27 \%$ no período de 2000 a 2012. Na Figura 4 pode ser visualizada esta expansão.

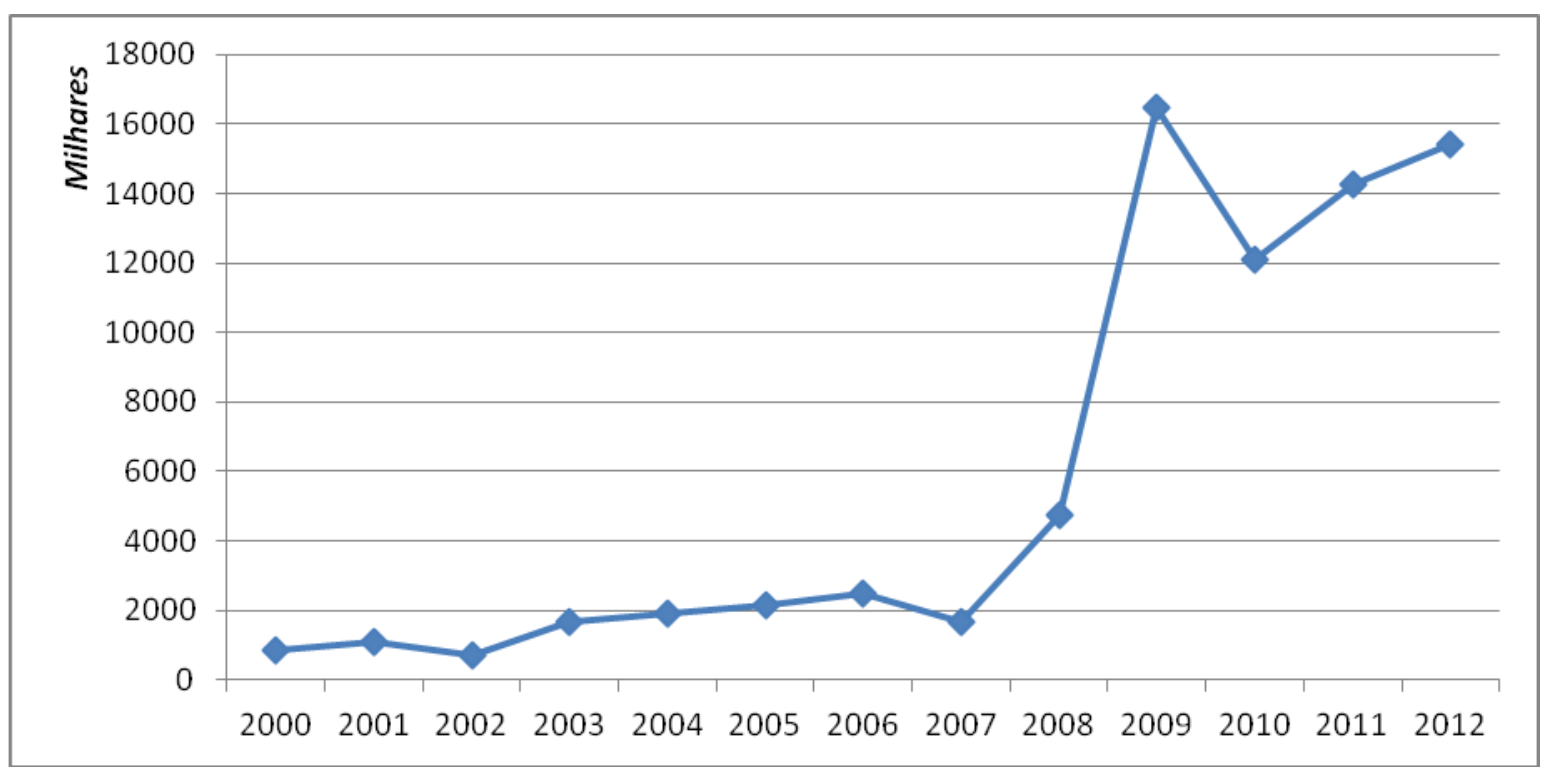

Fonte: BACEN (2014).

FIGURA 4 - Pronaf - Recursos para investimento agrícola no Estado de Goiás, 2000 a 2012. 
Quanto ao financiamento de Animais de Serviço, pode-se considerar insignificante, ocorrendo apenas em 2009, 2010 e 2011, num total de 15 contratos com valor de $\mathrm{R} \$ 16.057,54$. Essa modalidade é mais contemplada nos contratos de investimento pecuária. Para Veículos também é modesto o financiamento no período. Em relação ao montante dos recursos para investimento agrícola, sua participação foi de R $\$ 4.016 .710,96$ para aquisição de 86 unidades concentrada nos anos de 2010 e 2011. A Tabela 3 apresenta os dados para os anos de 2000, 2004, 2008 e 2011.

TABELA 3 - Modalidade de investimento agrícola financiados pelo Pronaf - Número de contratos, valor anual financiado e principais modalidades - Estado de Goiás - 2000, 2004, 2008 e 2011.

\begin{tabular}{|c|c|c|c|c|c|c|}
\hline \multirow[t]{2}{*}{ Ano } & \multirow[t]{2}{*}{ Contratos $\left(\mathrm{N}^{\mathrm{o}}\right)^{1}$} & \multirow[t]{2}{*}{ Valor Total $(\mathrm{R} \$)^{2}$} & \multicolumn{4}{|c|}{ Principais Modalidades ${ }^{3}$} \\
\hline & & & Nome & Valor $(\%)^{4}$ & Nome & Valor $(\%)$ \\
\hline 2000 & 186 & $873.323,32$ & FCP & 59,30 & $\mathrm{AO}$ & 21,20 \\
\hline 2004 & 121 & $1.924 .647,90$ & $\mathrm{MEq}$ & 51,76 & ME & 28,11 \\
\hline 2008 & 249 & $4.754 .438,62$ & $\mathrm{AO}$ & 38,87 & $\mathrm{MEq}$ & 25,17 \\
\hline 2011 & 550 & $14.261 .568,66$ & $\mathrm{MEq}$ & 52,28 & FCP & 15,32 \\
\hline
\end{tabular}

O Pronaf de investimento agrícola no período em questão, como demonstrado pelos dados das Tabelas 2 e 3, apresenta franco dinamismo e evolução muito positiva de indicadores. O número de contratos sofreu ampla expansão, de 186 em 2000 e ficando com 550 em 2011, sendo que o maior número foi em 2010 contemplando 836 contratos. De forma similar e crescente, os recursos aportados aumentaram anualmente, de forma significativa, partindo de em torno de novecentos mil reais em 2000 para mais de quatorze milhões em 2011.

Na Tabela 3 quanto as modalidades de investimento mais atendidas se destacam para Máquinas e Equipamentos (MEq) e Formação de Culturas Perenes (FCP). O maior destaque para o investimento em Máquinas e Equipamentos se deu em 2009, com o valor de $\mathrm{R} \$ 13.023 .959,36$ representando 79,16\% de todo o montante do ano. Ainda se apresenta significativo os investimentos anuais aplicados em Melhoramento de Explorações.

Pode-se afirmar que existe forte preocupação da política de crédito de investimento agrícola do Pronaf no sentido e melhor dotar os produtores familiares quanto à mecanização agrícola. Os reflexos desse esforço com maior acesso ao crédito pelo segmento podem estar contribuindo para maiores índices de produtividade das atividades agrícolas, assim como a rentabilidade da força de trabalho. 
O investimento na Formação de Culturas Perenes, aliado ao de Melhoramento de Explorações, representa uma política de acerto para sustentabilidade do produtor familiar. Como os aportes para essas modalidades são significativos, no período em análise, e, essas atividades representam diversidade de opções de renda, proporciona ao produtor melhor gestão dos seus negócios como obtenção de receitas em épocas de entressafra das culturas tradicionais.

\subsection{Financiamento Total Agrícola - Custeio e Investimento no Estado de Goiás}

Os dados da Tabela 4 indicam a prioridade da política de crédito agrícola do Pronaf, em Goiás, dando maior prioridade ao financiamento do custeio em detrimento do de investimento. De 2000 até 2008, inclusive, mais de 96\% dos contratos foram assinados para custeio e os valores anuais alocados foram superiores aos $90 \%$ dos montantes totais. Isso não quer importar numa política de erro ou equivocada, pelo contrário, como o Pronaf pode ser considerado um programa de políticas para agricultura familiar, ainda recente, que sofre ajustes em diversas áreas de sua gestão. Como bom sinal desses ajustes é que passa ocorrer, a partir de 2009, maiores aportes de financiamento de investimento comparado com os de custeio. Como já analisado anteriormente, valores mais abrangentes para financiamento de máquinas e equipamento, formação de culturas perenes e recursos para seus melhoramentos já passam a ocorrerem nos anos do final da década. Isso pode colaborar para a afirmação e superação das limitações do segmento da agricultura familiar goiana, principalmente quanto à qualidade de vida e sustentabilidade econômica.

TABELA 4 - Pronaf agrícola total e Relações Custeio/Investimento - Goiás: 2000-2011.

\begin{tabular}{|c|c|c|c|c|c|c|}
\hline \multirow[t]{3}{*}{ Ano } & \multicolumn{2}{|c|}{ Pronaf Agrícola Total } & \multicolumn{4}{|c|}{ Relação do Pronaf Agrícola Total } \\
\hline & \multirow[t]{2}{*}{ Contratos $\left(\mathrm{N}^{\circ}\right)$} & \multirow{2}{*}{$\begin{array}{l}\text { Valor } \\
(\mathrm{R} \$)\end{array}$} & \multicolumn{2}{|c|}{ Custeio/Total } & \multicolumn{2}{|c|}{ Investimento/Total } \\
\hline & & & Contratos $(\%)$ & Valor $(\%)$ & Contratos $(\%)$ & Valor $(\%)$ \\
\hline 2000 & 3.436 & $11.710 .136,48$ & 94,59 & 92,59 & 5,41 & 7,46 \\
\hline 2001 & 3.510 & $13.749 .387,31$ & 97,26 & 92,14 & 2,74 & 7,86 \\
\hline 2002 & 4.168 & $12.708 .461,20$ & 98,49 & 94,45 & 1,51 & 5,55 \\
\hline 2003 & 10.162 & 35.313.093,39 & 98,62 & 95,23 & 1,38 & 4,77 \\
\hline 2004 & 12.411 & $63.588 .206,70$ & 99,03 & 96,97 & 0,97 & 3,03 \\
\hline 2005 & 9.874 & $61.174 .427,13$ & 97,78 & 96,47 & 2,22 & 3,53 \\
\hline 2006 & 8.755 & $60.102 .764,05$ & 97,41 & 95,88 & 2,59 & 4,12 \\
\hline 2007 & 8.254 & $59.467 .860,19$ & 97,77 & 97,18 & 2,23 & 2,82 \\
\hline 2008 & 6.598 & $58.122 .430,03$ & 96,23 & 91,82 & 3,77 & 8,18 \\
\hline 2009 & 5.767 & $67.408 .829,29$ & 89,09 & 75,59 & 10,91 & 24,41 \\
\hline 2010 & 4.826 & $58.705 .056,87$ & 82,68 & 79,41 & 17,32 & 20,59 \\
\hline 2011 & 3.383 & $56.671 .445,39$ & 83,74 & 74,83 & 16,26 & 25,17 \\
\hline
\end{tabular}

Fonte: BACEN (2014) 


\subsection{O desempenho do Pronaf Pecuária em Goiás}

Diferentemente do comportamento do Pronaf agrícola, tanto o de custeio quanto o de investimento, no período em análise, o Pronaf pecuária apresenta uma evolução consistente e de razoável regularidade, quanto aos contratos contemplados e os montantes alocados de crédito, anualmente, como os dados mostram na Tabela 5.

TABELA 5 - Pronaf pecuária - Custeio e Investimento - Estado de Goiás: 2000 -2011.

\begin{tabular}{rrrrrrr}
\hline Ano & \multicolumn{3}{c}{ Custeio } & \multicolumn{3}{c}{ Investimento } \\
\hline & $\begin{array}{c}\text { Contratos } \\
\left(\mathrm{N}^{\circ}\right)\end{array}$ & $\begin{array}{c}\text { Valor } \\
(\mathrm{R} \$)\end{array}$ & $\begin{array}{c}\text { Média dos } \\
\text { Contratos } \\
(\mathrm{R} \$)\end{array}$ & $\begin{array}{c}\text { Contratos } \\
\left(\mathrm{N}^{\circ}\right)\end{array}$ & \multicolumn{1}{c}{$\begin{array}{c}\text { Valor } \\
(\mathrm{R} \$)\end{array}$} & $\begin{array}{c}\text { Média dos } \\
\text { Contratos } \\
(\mathrm{R} \$)\end{array}$ \\
\hline 2000 & 3.540 & $15.586 .339,22$ & $4.402,92$ & 1.254 & $9.748 .439,04$ & $7.773,38$ \\
2001 & 6.017 & $27.874 .819,22$ & $4.632,67$ & 3.397 & $32.728 .589,23$ & $9.634,55$ \\
2002 & 6.652 & $29.355 .847,63$ & $4.413,08$ & 1.702 & $20.073 .772,39$ & $11.794,22$ \\
2003 & 10.825 & $48.885 .133,22$ & $4.515,94$ & 1.883 & $23.855 .705,94$ & $12.668,98$ \\
2004 & 13.212 & $74.216 .420,69$ & $5.617,34$ & 5.520 & $61.155 .034,43$ & $11.078,81$ \\
2005 & 14.956 & $87.935 .507,84$ & $5.879,61$ & 6.735 & $71.906 .006,16$ & $10.676,46$ \\
2006 & 16.270 & $97.447 .989,97$ & $5.989,42$ & 7.523 & $75.271 .921,24$ & $10.005,57$ \\
2007 & 16.932 & $108.076 .046,35$ & $6.382,94$ & 5.773 & $62.287 .371,95$ & $10.789,42$ \\
2008 & 16.282 & $125.250 .453,33$ & $7.692,57$ & 6.968 & $87.632 .335,42$ & $12.576,39$ \\
2009 & 16.221 & $150.766 .733,76$ & $9.300,27$ & 8.606 & $177.444 .183,43$ & $20.618,65$ \\
2010 & 15.590 & $168.139 .112,49$ & $10.785,06$ & 7.836 & $203.209 .932,25$ & $25.932,86$ \\
2011 & 14.781 & $179.025 .655,24$ & $12.111,87$ & 7.029 & $194.910 .125,25$ & $27.729,42$ \\
\hline
\end{tabular}

Fonte: BACEN (2014).

Por exemplo, no tocante ao custeio da pecuária, ocorre um crescente atendimento das demandas anuais dos contratos, como em 2000 a demanda foi de 3.540 financiando um valor de mais de quinze milhões de reais, e, em 2011, foi atendido 14.781 contratos no valor de $\mathrm{R} \$ 179.025 .655,24$. É notório que quanto ao custeio da pecuária, para àqueles agricultores que optaram por essa exploração agrícola para se afirmarem na atividade, a gestão do Pronaf foi eficiente.

Na Figura 5 apresenta a evolução deste período analisado para o custeio da pecuária no Estado de Goiás. A taxa geométrica de crescimento do período foi de $21 \%$. Nesta modalidade não ocorreu reduções em nenhum período analisado e os dados indicam um crescimento constante dos volumes alocados para esta atividade, podendo indicar uma tendência das políticas públicas favorecem a pecuária para os pequenos produtores devido a sua importância na geração de renda e melhoria da qualidade de vida deste segmento. 


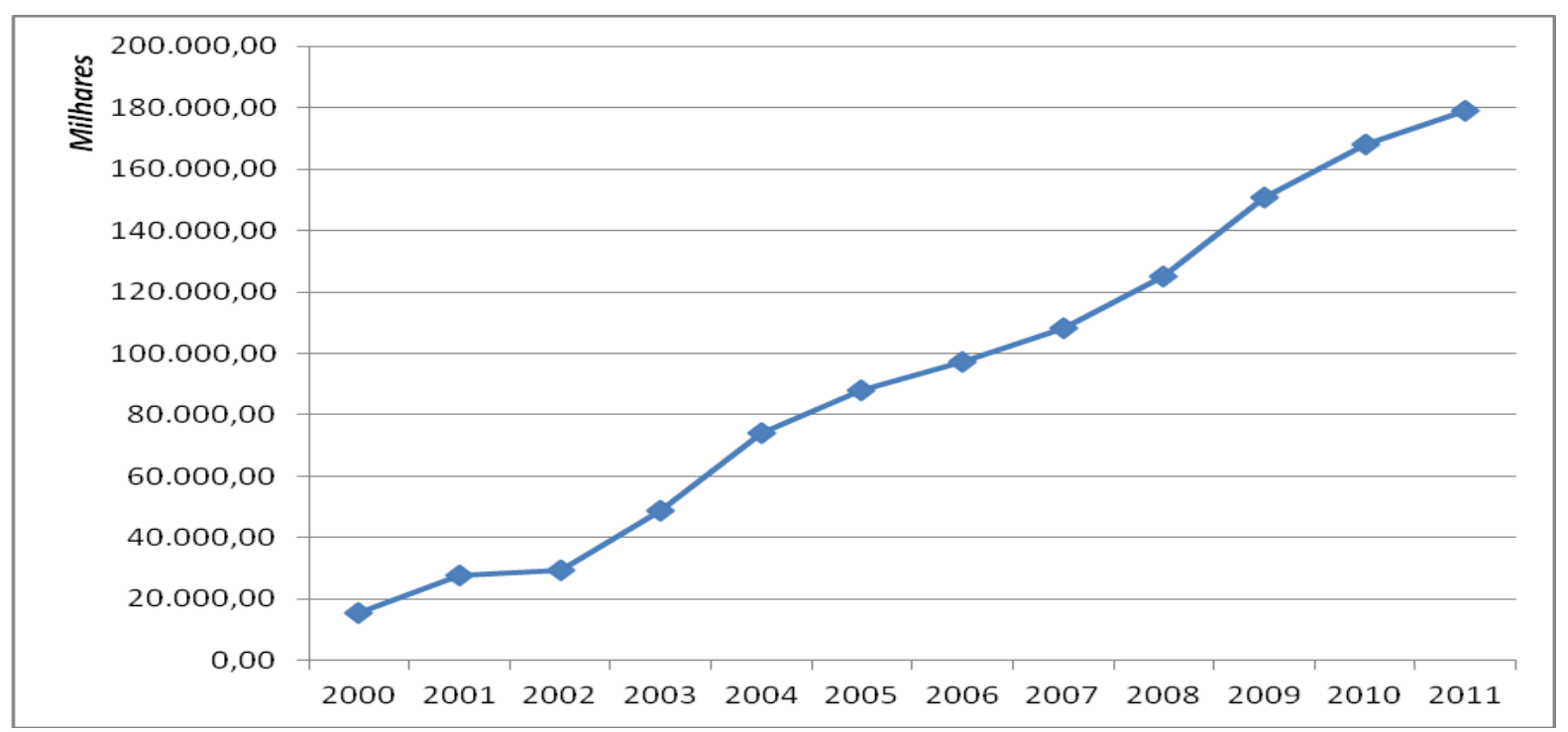

Fonte: BACEN (2014).

FIGURA 4 - Pronaf - Recursos para investimento agrícola no Estado de Goiás, 2000 a 2012.

De forma similar ao custeio da pecuária, as informações quanto ao investimento na pecuária demonstram, sem dúvida, certa pertinência e coerência dos investimentos anuais para dotar os agricultores familiares de condições de ativos, tanto de animais, equipamentos e outras tecnologias, quanto de gestão dos seus negócios, para que pudessem alavancar suas atividades pecuárias. Em 2000, foram assinados 1.254 contratos de investimento demandando mais de nove milhões de reais. O valor financeiro médio dos contratos foi em torno de oito mil reais, por contrato. Em 2011, sete mil contratos foram contemplados, os recursos chegaram perto dos duzentos milhões de reais, e, o mais significativo foi que o valor médio dos contratos atingiu $\mathrm{R} \$ 27.729,42$.

Pelo demonstrado nos dados do Pronaf Pecuária, pode-se concluir que o programa está no caminho certo. Até porque, a atividade principal financiada é da exploração de leite, que assegura uma receita mensal ao agricultor. Daí o planejamento da gestão financeira do agricultor torna-se mais fácil no sentido de cumprir com seus compromissos junto ao programa e projetar avanços, via novos créditos, para aumentar sua renda.

O custeio da pecuária a partir de 2000 foi centrado majoritariamente na manutenção dos animais bovinos para a produção de leite e das atividades de melhoramento das atividades, como possivelmente na formação e recuperação de pastagens, aquisição de insumos como sal mineral, medicamentos, rações apropriadas e outros como demonstrado pelos dados da Tabela 6, em consonância com os da Tabela 7. 
TABELA 6 - Principal atividade e principais produtos da modalidade de Custeio Pecuária financiados pelo Pronaf, no Estado de Goiás, nos anos 2000, 2004, 2008 e 2011.

\begin{tabular}{rrrrrrr}
\hline Ano & Contratos $\left(\mathrm{N}^{\circ}\right)^{1}$ & Valor Total $(\mathrm{R} \$)^{2}$ & \multicolumn{4}{c}{ Principais Modalidades $^{3}$} \\
& & & Nome & Valor $(\%)^{4}$ & Nome & Valor $(\%)$ \\
\hline 2000 & 3.540 & $15.586 .339,22$ & Crédito Rotativo & 96,20 & Animais & 3,73 \\
2004 & 13.212 & $74.216 .420,69$ & Animais & 100,00 & - & - \\
2008 & 16.282 & $125.250 .453,33$ & Animais & 99,99 & Outras & 00,01 \\
2011 & 14.781 & $179.025 .655,24$ & Animais & 100,00 & - & - \\
\hline
\end{tabular}

${ }^{1}$ Número total dos contratos de custeio pecuária. ${ }^{2}$ Valor total financiado. ${ }^{3}$ Em 2000, 2001, 2002, 2003 e 2005 existiam as modalidades de: Animais, Beneficiamento ou Industrialização, Crédito Rotativo e Outras Aplicações. Nos demais anos não consta o Crédito Rotativo. ${ }^{4}$ Os percentuais dos valores financiados das principais modalidades são referentes aos valores totais anuais.

Como esclarecimento, de 2000 até 2003, aparece na Tabela 6 a referência de custeio de Crédito Rotativo que significa o financiamento das atividades concernentes à manutenção da atividade da pecuária de leite. A partir de 2004 a modalidade financiada, anualmente, atende ao denominado Animais.

TABELA 7 - Modalidade de Investimento Pecuária financiados pelo Pronaf - Número de contratos, valor anual financiado e principais modalidades - Estado de Goiás - 2000, 2004, 2008 e 2011.

\begin{tabular}{rrrrrrr}
\hline Ano & Contratos $\left(\mathrm{N}^{\circ}\right)^{1}$ & Valor Total $(\mathrm{R} \$)^{2}$ & \multicolumn{3}{c}{ Principais Modalidades $^{3}$} & \multicolumn{1}{c}{ Valor $(\%)$} \\
\hline 2000 & & & Nome & Valor $(\%)^{4}$ & Nome & M.E \\
2004 & 1.254 & $9.748 .439,04$ & A.A & 58,90 & M.E & 27,51 \\
2008 & 5.520 & $61.155 .034,43$ & A.A & 66,07 & O.A & 10,49 \\
2011 & 6.968 & $87.632 .335,42$ & A.A & 75,95 & O.A & 5,53 \\
\hline
\end{tabular}

${ }^{1}$ Número total dos contratos de investimento pecuária. ${ }^{2}$ Valor total financiado. ${ }^{3}$ As modalidades são: A.S (Animais de Serviço); O.A (Outras Aplicações); M.Eq (Máquinas e Equipamentos); M.E (Melhoramento de Explorações); A.A (Aquisição de Animais); V (Veículos ${ }^{4}$ Os percentuais dos valores financiados das principais modalidades são referentes aos valores totais de investimento.

Fonte: BACEN (2014).

Os dados da Tabela 7 mostram sem dúvida que os montantes de recursos destinados ao financiamento de investimento da pecuária foram, majoritariamente, para a modalidade de Aquisição de Animais. Os contratos contemplados a partir de 2000, com 1.254, evoluíram significativamente para em torno de sete mil em 2011. Assim como os valores financiados que, em 2000 foram da ordem de próximo de dez milhões de reais, evoluíram exponencialmente para $\mathrm{R} \$ 194.910 .125,25$. Pode-se assegurar que houve avanços substanciais ao acesso ao crédito do segmento da agricultura familiar goiana, o que demonstra que a política creditícia do Pronaf está evoluindo positivamente no Estado de Goiás.

Corroborando com a assertiva acima, as informações da Tabela 8 indicam uma pertinência da evolução, tanto do número de contratos atendidos (produtores) quanto dos recursos disponibilizados. De fato, nessa década, sem considerar outros fatores restritivos e ainda, possivelmente, algum contingente não atendido da agricultura familiar goiana, é 
notório o esforço que fora dispendido pela política do Pronaf. Pois, em 2000 foram atendidos, no total, 4.794 contratos de custeio e investimento, e, em 2011 foram 21.810. Os recursos disponibilizados saltaram de vinte e cinco milhões de reais em 2000 para $\mathrm{R} \$ 373.935 .780,49$ em 2011. Por isso, como já analisado os dados da Tabela 5, a média dos contratos tiveram crescentes aumentos anuais que significa evidências de sustentabilidade das atividades econômicas desenvolvidas pelos produtores familiares.

TABELA 8 - Pronaf Pecuária Total e Relações Custeio/Investimento - Goiás: 2000-2011.

\begin{tabular}{|c|c|c|c|c|c|c|}
\hline \multirow[t]{3}{*}{ Ano } & \multicolumn{2}{|c|}{ Pronaf Pecuária Total } & \multicolumn{4}{|c|}{ Relação do Pronaf Pecuária Total } \\
\hline & \multirow[t]{2}{*}{ Contratos $\left(\mathrm{N}^{\circ}\right)$} & \multirow[t]{2}{*}{ Valor $(\mathrm{R} \$)$} & \multicolumn{2}{|c|}{ Custeio/Total } & \multicolumn{2}{|c|}{ Investimento/Total } \\
\hline & & & Contratos $(\%)$ & Valor $(\%)$ & Contratos $(\%)$ & Valor $(\%)$ \\
\hline 2000 & 4.794 & $25.334 .778,26$ & 73,84 & 61,52 & 26,16 & 38,48 \\
\hline 2001 & 9.414 & $60.603 .408,23$ & 63,92 & 46,00 & 36,08 & 54,00 \\
\hline 2002 & 8.354 & $49.429 .620,02$ & 79,63 & 59,39 & 20,37 & 40,61 \\
\hline 2003 & 12.708 & $72.740 .839,16$ & 85,18 & 67,20 & 14,82 & 32,80 \\
\hline 2004 & 18.732 & $135.371 .455,12$ & 70,53 & 54,82 & 29,47 & 45,18 \\
\hline 2005 & 21.691 & $159.841 .514,00$ & 69,14 & 55,01 & 30,86 & 44,99 \\
\hline 2006 & 23.793 & 172.719.911,21 & 68,38 & 56,42 & 31,62 & 43,58 \\
\hline 2007 & 22.705 & $170.363 .418,30$ & 74,57 & 63,44 & 25,43 & 36,56 \\
\hline 2008 & 23.250 & $212.882 .788,76$ & 70,03 & 58,84 & 29,97 & 41,16 \\
\hline 2009 & 24.827 & $328.210 .917,19$ & 65,34 & 45,94 & 34,66 & 54,06 \\
\hline 2010 & 23.426 & $371.349 .044,74$ & 66,55 & 45,28 & 33,45 & 54,72 \\
\hline 2011 & 21.810 & $373.935 .780,49$ & 67,77 & 47,88 & 32,23 & 52,12 \\
\hline
\end{tabular}

Fonte: BACEN (2014).

Vale ressalvar que as relações Custeio/Total e Investimento/Total, expressas nos percentuais dos contratos contemplados e dos valores financiados, respectivamente, apresentam coerência quanto à evolução durante o período em estudo. É pertinente que o processo tenha evoluído com maior atenção ao atendimento das demandas do custeio e com o passar dos anos foram sendo atendidas às de investimento. Até porque nessas atividades, como da pecuária de leite e outras atividades agrícolas, há necessidade de um período relativamente longe para a maturação das mesmas. O que de fato vem ocorrendo, a partir de 2004 , com o financiamento quase equilibrado tanto para o custeio quanto para o investimento na pecuária.

\section{CONSIDERAÇÕES FINAIS}

O Pronaf tem, desde a sua concepção em 1996, dois fundamentos essenciais que norteiam sua política pública. Por um lado, a consideração da base social das unidades familiares de produção, por outro, o financiamento visando à sustentabilidade econômica dos empreendimentos produtivos. Esses fundamentos, independentemente do nível de renda e das 
peculiaridades dos agentes atendidos, deram escopo e dinâmica na legislação pertinente, inclusive dos posteriores aprimoramentos que a ela foram anexados.

De início, a legislação teve caráter genérico, mas com foco específico na agricultura familiar, deixando pouca possibilidade de desvios na sua operacionalização. Não seria de outra forma o surgimento dessa legislação, haja vista a enorme diversidade dos segmentos que constituem a agricultura familiar, historicamente, existentes nas diversas regiões brasileiras. Apesar do restrito atendimento inicial, que contemplou melhor o segmento familiar com atividade econômica já com integração contratual com a agroindústria, em seguida e de forma crescente, diversos outros segmentos passaram a ter acesso ao crédito de acordo com sua renda e especificidade econômica.

Apesar do incremento constante dos recursos alocados e executados do Pronaf, anualmente, e da sua expansão na base social da agricultura familiar, persistem algumas preocupantes medidas de política pública creditícia, graves distorções regionais além de dificuldades de expansão e aplicação de recursos de investimento. Um dos entraves para a afirmação, agregação de valor dos produtos e aumento da renda bruta está associado ao baixo nível tecnológico empregado pela agricultura familiar. Por sua vez, a baixa disponibilidade de crédito de investimento e as dificuldades de acesso pelos agricultores familiares corroboram para manter esse quadro.

Uma sugestão que poderia ser implantada seria a formação de grupos de agricultores, intermediados por cooperativas e/ou associação, para formar consórcios para aquisição de maquinários, plantel de animais e insumos agrícolas. Quanto aos dados analisados para o Estado de Goiás conclui-se que ocorreu no período analisado uma significativa evolução das modalidades do Pronaf agrícola e pecuária o que tem significou uma maior inserção dos produtores familiares, pois os dados indicam um aumento do volume de contratos para o mesmo período. Outro fator importante detectado é o crescimento da média de contratos. $\mathrm{O}$ acesso a um volume maior de recursos pode significar em alguns casos uma inserção mais produtiva destes segmentos familiares no mercado.

Destaca-se, ainda que o setor da pecuária mantém sua importância histórica na produção familiar com a geração da renda mensal, através da pecuária leiteria, tornando-a a principal atividade dos pequenos produtores goianos. O volume de recursos destinados aos investimentos da pecuária para os produtores do Pronaf em Goiás apresentou o crescimento mais significativo do período analisado. A modalidade de aquisição de animais apresenta a maior participação entre as opções de investimentos da pecuária indicando uma estratégia de 
melhoria dos rebanhos dos produtores rurais. Conclui-se que esta opção tem como meta a consolidação desta atividade para a geração e inserção do produtor familiar no mercado goiano.

\section{REFERÊNCIAS}

ABRAMOVAY, R. Paradigmas do capitalismo agrário em questão. São Paulo, Hucitec: Edunicamp: Anpocs, 1998.

ABRAMOVAY, R.; PIKETTY, M.-G. Política de crédito do Programa Nacional de Fortalecimento da Agricultura Familiar (PRONAF): resultados e limites da experiência brasileira nos anos 90. Cadernos de Ciência \& Tecnologia, Brasília, v.22, n.1, p.53-66, jan./abr. 2005.

ALTAFIN, I.(2012). Reflexões sobre o conceito de agricultura familiar. Disponível em <

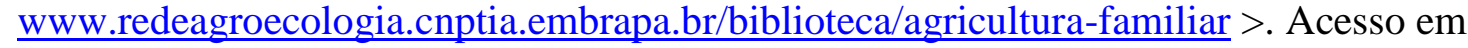
27/09/2012.

BITTENCOURT, G. A. Abrindo a caixa preta: o financiamento da agricultura familiar no Brasil. 2003. 227 f. Dissertação (Mestrado em Economia Rural) - IE/Unicamp. Campinas, SP.

BRASIL. Presidência da República. Decreto n. 1946, de 28 de junho de 1996. Cria o Programa o Programa Nacional de Fortalecimento da Agricultura Familiar - PRONAF, e dá outras providências., 2012. Disponível em < $\underline{\text { www.Pronaf.gov.br }}>$. Acesso em 5 out. 2014.

BRASIL. Controladoria-Geral da União. Orientações para o acompanhamento dos Programas de Desenvolvimento Agrário. Brasília, DF, 2012. Disponível em < www.cgu.gov.br/Publicacoes/CartilhaOlhoVivo/Arquivos/DesenvolvimentoAgrario2012pdf >. Acesso em 24 set. 2014.

BRASIL. (2012). Lei 12.058, de 13 de outubro de 2009. Dispõe sobre a prestação de apoio financeiro pela União aos entes federados que recebem recursos do Fundo de Participação dos Municípios - FPM, no exercício de 2009, com o objetivo de superar dificuldades financeiras emergenciais; altera as Leis ... e o art. 13 da Lei ${ }^{\circ} 11.326$, de 13 de julho de 2006; e dá outras providências. Disponível em < www.planalto.gov.br/ccivil $>$. Acesso em 10 out. 2014.

BRASIL. Ministério do Desenvolvimento Agrário. Cartilha de acesso ao PRONAF: Saiba como obter crédito para a agricultura familiar. Brasília, 2011.

JUNQUEIRA, R.; ABRAMOVAY, R. A sustentabilidade das microfinanças solidárias.

Revista de Administração da USP, São Paulo, v. 40, n. 1, p. 19-23, 2005.

MORAES, C. L. de; LIMA, D. A. L. L. Viabilidade Econômica da Cultura do Algodão em Propriedades Familiares no Sudoeste de Goiás. Rio Verde - GO: Faculdade de Ciências Econômicas da Universidade de Rio Verde, 2005. 49p. 
ROSA, S. L. C. Desafios do Pronaf - Programa Nacional de Fortalecimento da Agricultura Familiar. Revista Reforma Agrária, Campinas: ABRA, v. 25, n. 2 e 3, p. 185-192, maio-dez. 1995.

SERVOLIN, C. L'absorption de l'agriculture dans le mode de production capitaliste. In: GERVAIS, M.; SERVOLIN, C.; TAVERNIER,Y. (Ed.). Lúnivers politique des paysans dans la France contemporaine. Paris: Armand Colin, 1972, 653.

SOUZA, C. B.; CAUME, D. J. Crédito rural e a agricultura no Brasil. 2008. Disponível em < www.sober.org.br/palestra/9/882.pdf $>$. Acesso em 15/11/2012.

VEIGA, J. E. O desenvolvimento agrícola: uma visão histórica. São Paulo, Hicitec: Edusp, 1991.

SOUZA, P. M. et al. Agricultura Familiar Versus Agricultura Não-Familiar: uma Análise das Diferenças nos Financiamentos Concedidos no Período de 1999 a 2009. Documentos Técnico-Científicos, v. 42, n. 01, jan./mar. 2011. 